\title{
INCORPORATION OF RUBBER-STEEL BEARING ISOLATION IN MULTI-STOREY BUILDING
}

\author{
A. B. M. Saiful ISLAM ${ }^{\mathrm{a}}$, Mohd Zamin JUMAAT ${ }^{\mathrm{a}}$, Raja HUSSAIN ${ }^{\mathrm{b}}, \mathrm{Md}_{\mathrm{Ashraful}}$ ALAM $^{\mathrm{c}}$ \\ ${ }^{a}$ Department of Civil Engineering, University of Malaya, Kuala Lumpur, Malaysia \\ ${ }^{b}$ CoE-CRT, Department of Civil Engineering, King Saud University, Riyadh, Saudi Arabia \\ ${ }^{c}$ Department of Civil Engineering, University Tenaga Nasional, Kuala Lumpur, Malaysia
}

Received 6 Jan 2012; accepted 14 Feb 2012

\begin{abstract}
Base isolation incorporation has moved towards a popular technology in the seismic vulnerable regions. The system mitigates lateral action of tremor hazard providing flexibility of structures. Implementing base isolation on buildings in the soil and seismic condition of medium risk seismicity is currently an important issue. A thorough investigation is of burning need for buildings to be incorporated with base isolator and to carry out dynamic analysis. The study provides incorporation of rubber-steel bearings and focuses on the structural changes. Designs of base isolation bearings are performed along with structural viability check. Lead rubber bearing (LRB) and high damping rubber bearing (HDRB) have been inserted on the corresponding structural bases. In finite-element approach, link element simulates the bearing. Bi-linear hysteretic behaviour is presented for LRB and equivalent linear model simulated HDRB. Linear static, free vibration and dynamic frequency-domain analyses are performed for both isolated and non-isolated buildings under bidirectional sitespecific earthquake. The study reveals that for multi-storey buildings, isolation can drastically reduce seismic responses. Furthermore, flexibility of buildings predicts some structural savings for reduced responses. Good agreement has been achieved through rapid solution in frequency-domain approach. In medium risk earthquake-prone area, rubber-steel bearing isolators can be beneficially inserted.
\end{abstract}

Keywords: frequency domain, response spectrum, site-specific time history, free vibration, rubber-steel bearing, seismic isolation, medium risk seismicity.

Reference to this paper should be made as follows: Islam, A. B. M. S.; Jumaat, M. Z.; Hussain, R.; Alam, M. A. 2013. Incorporation of rubber-steel bearing isolation in multi-storey building, Journal of Civil Engineering and Management 19(Supplement 1): S33-S49. http://dx.doi.org/10.3846/13923730.2013.801904

\section{Introduction}

Increasing global demand of multi-storey structures is looking forward to the efficient design solution to tackle the vulnerable seismic hazard. Recent smart approach like base isolation aimed at fortification of building structures serves as competent alternative technology against the expected level of ground excitation. The isolation strategy is rapidly being popular than the widely adopted seismic strengthening technique. The technique is the separation of the structure from destructive ground motions ensuring flexibility as well as energy dissipation aptitude through insertion of isolation device between the foundation and superstructure (Islam et al. 2011a; Ismail et al. 2010). A foremost portion of the seismic energy which would be transferred into the structure is absorbed at the base level. Consequently, the ductility demand to the structure is reduced in substantial manner. In addition, the frequency of isolated based structure reduces to an extent below that which dominates in a typical earthquake. Instead of the traditional dealings design based upon an increased resistance by strengthening of the structures, base isolation idea is intended for a weighty lessening of dynamic loading exhibited by earthquake motion at the structural base.

The rubber-steel isolator like lead rubber bearing (LRB, 1970's) and high damping rubber bearing (HDRB, early 1980's) provide a new-fangled aspect to the implementation of base isolation in structures (Islam et al. 2012 a, b). Several research works in the expanse of base isolation focused on the incorporation of elastomeric bearings namely LRB and HDRB isolators (Islam et al. 2013a). Dall'Asta and Ragni (2006, 2008) have dealt with experimental tests, presenting analytical model and evaluation of nonlinear dynamic behaviour of HDRB. Jangid (2007) and Providakis (2008) explored the responses of aseismic multi-storey buildings isolated by LRB at near fault motion. Incorporation of this innovative seismic isolation system was well evaluated and reviewed for multi-storey buildings (Agarwal et al. 2007; Komodromos 2008; Lu, Lin 2008; Seçer, Bozdağ 2011; Spyrakos et al. 2009). Base isolator with hardening 
behaviour under increasing loading has been presented for medium-rise buildings positioned at moderate earthquake risk (Pocanschi, Phocas 2007). Ariga et al. (2006) evaluated the resonant behaviour of base-isolated highrise buildings under long-period ground motions. In addition, the long period building responses with isolating strategy were accomplished by Olsen et al. (2008). Dicleli and Buddaram (2007) and Casciati and Hamdaoui (2008) have added their effort in advancements of rubber bearing isolation in multi-storey structures. Islam et al. (2013b) studied the optimisation in structural altitude for isolation system and efficient design (Islam et al. 2013c) in multi-storey buildings using HDRB and LRB in building base.

Still there is prodigious lacking of apposite study to practically incorporate the rubber-steel bearing device for the medium risk seismic region. Therefore, a thorough study in this area is an especially burning matter. Again bidirectional earthquake consideration has been rarely done. Furthermore, the time domain method is relatively more time consuming, lengthy, and costly. The frequency domain method, on the other hand, is relatively more rapid, concise, and economical. In this study, dynamic analysis in frequency domain under bidirectional sitespecific earthquake loading has been carried out. Combined configuration of HDRB and LRB is modelled to explore the isolation viability. Preliminary exploration for suitability of incorporating isolator has been done with equivalent static analysis. Then dynamic analysis in frequency domain has been performed to satisfy the structural limitation executing different comparative contribution. The study area Dhaka, Bangladesh, has been chosen to suit the medium risk seismic condition. Design parameters of isolator have been evaluated. The finite element modelling has been developed and the analyses of multi-storey structure are performed by sophisticated finite element code SAP 2000 (CSI 2004). Static analysis and free vibration analysis (Betti, Vignoli 2011; Ho, Zhou 2011; Jameel et al. 2012; Patil, Jangid 2011) were performed along with dynamic analysis in frequency domain. The acceleration excitation behaviours for fixed and isolated buildings were assessed with the displacement patterns at different levels as well. In addition, base shear and overturning moments are compared for both the fixed based and isolated based cases. Every comparison has been enforced mentioning the maximum and minimum values on structural excitation. Significant reductions of structural responses have been observed. Furthermore, flexibility of structure has been experienced through seismic base isolation.

\section{Structural model}

Moment resisting reinforced concrete frame structure is considered to model the multi-storey building in this study. The superstructure has been simulated by means of a linear elastic system for the conventional fixed based building. The idealised configuration of the multistoried building structure has been shown in Figure 1. Rubber-steel bearings are incorporated in between the foundation and superstructure where nonlinear behaviour is confined in rubber-steel bearing isolators. Base and floors of the multi-storey building are supposed to be infinitely rigid. The structural system follows subsequent assumptions:

1) The superstructure and the base of the building have been configured using 6 degrees of freedom at the centre of mass of apiece floor;

2) The superstructure behaves elastic and inelastic during earthquake excitation;

3) Floors are considered as rigid in own plane and mass is lumped at every respective floor;

4) Total structural configuration is excited by bidirectional components of earthquake ground motion ( $\mathrm{x}$ - and $\mathrm{y}$-directions);

5) Base isolators convey the vertical load undergoing no vertical deformation;

6) Bi-linear model simulates LRB, and equivalent linear model is selected for HDRB;

7) The rubber-steel bearings are fixed at bottom to the foundation and at top with the base mass.
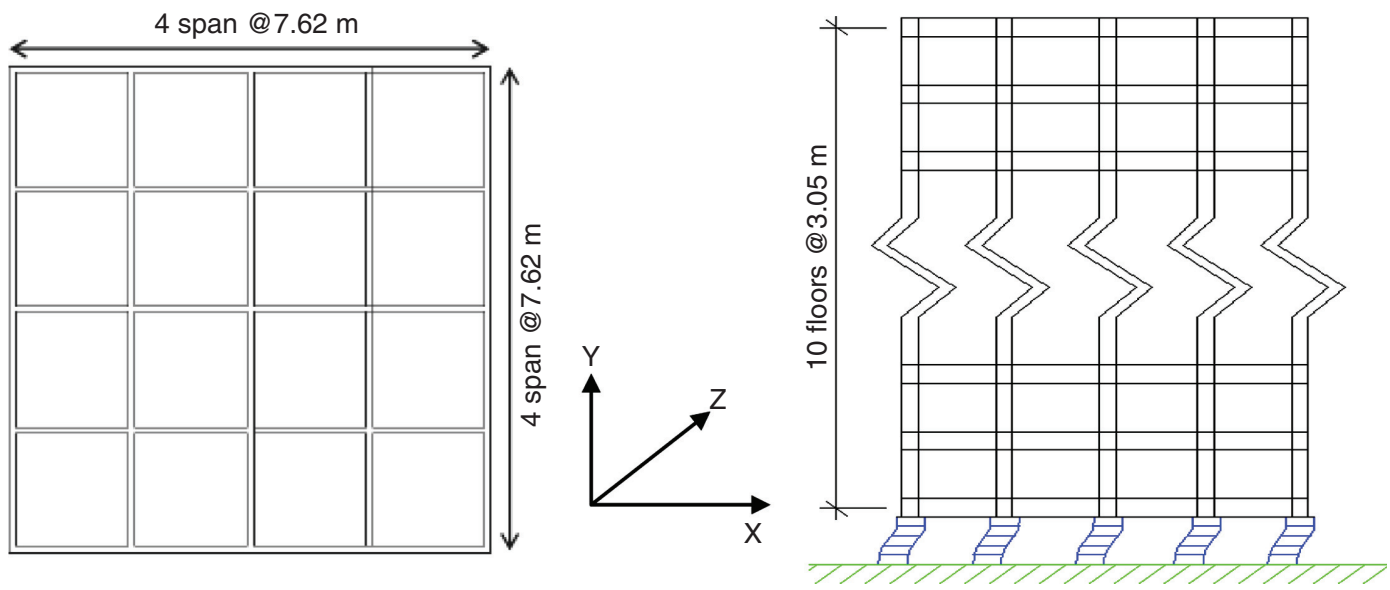

Fig. 1. Structural model of the multi storied building (fixed or isolated-based) 


\subsection{Mathematical formulation}

Base isolated structures require dynamic analysis for its level of complexity. Here SAP2000 programme has been found appropriate for static and dynamic analysis provided a linear elastic structure. The isolators HDRB and LRB are designed first as per different properties and adopting the static design procedure. The bearings were then linked at the base of the building structures and analysed accordingly. Dynamic analysis in frequency domain has been done for both fixed based and isolated case. Design of bearings has been done with the developed programme DESBEA formulated by the equations and conditions. The flow charts for consecutive design of isolator are given for both HDRB and LDRB (Fig. 2).

\subsection{Modelling of isolators}

A hysteresis model is intended to provide the stiffness and resistance under any displacement history. In addition, the basic characteristics are defined through member geometry and material properties. To carry out response spectrum analysis, effective stiffness $\left(K_{\text {eff }}\right)$ and the equivalent viscous damping derived from the isolator's EDC (energy Dissipated per Cycle) are essential. Forcedeformation behaviours of the isolators in this study are modelled as numbered (1) for LRB and (2) for HDRB:

1) Nonlinear hysteretic loop directly specified by the bi-linear model; and

2) Equivalent linear elastic model with viscous damping included for the nonlinear system.

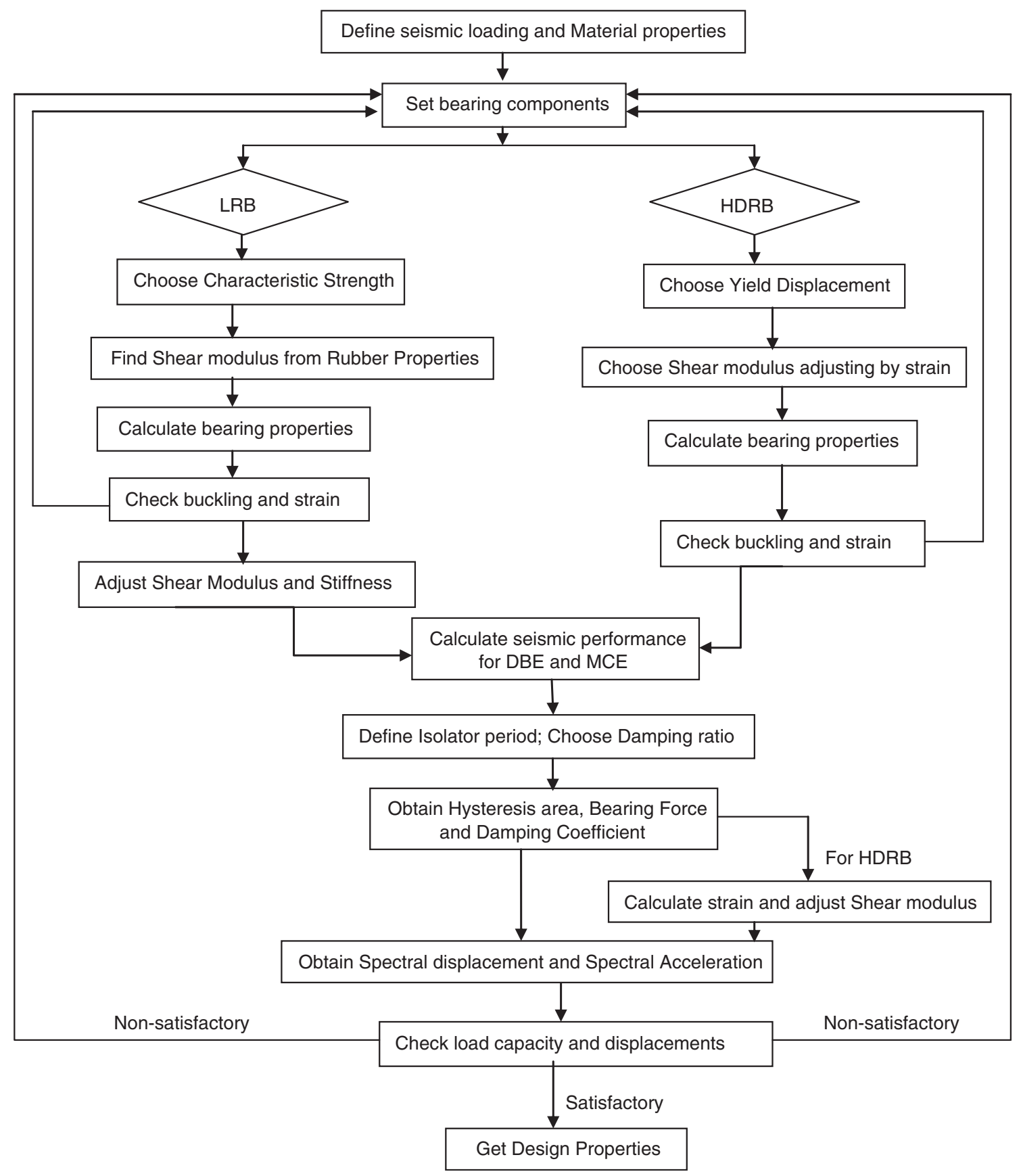

Fig. 2. Design flow chart of Rubber-steel bearing 


\subsubsection{LRB bi-linear model}

LRB is formed by force-fitting a lead plug into a preformed hole in a low damping elastomeric bearing (Win 2008) as presented in Figure 3a. Basic components of such bearing are rubber and steel plates built in alternate layers. The steel plates force the lead plug in the bearing to deform in shear. The LRB system offers the parallel action of linear spring and damping. The system decouples the structure from the horizontal components of earthquake ground motion by interjecting a layer of low horizontal stiffness between foundation and superstructure. Generally, the LRB exhibits required amount of damping, horizontal flexibility as well as high vertical stiffness. Large difference in damping of the structure and the isolation device makes the system non-classically damped. Such physiognomies lead to coupling of the equations of motion. Elastic-perfectly plastic hysteretic model was used to cope with the essential isolation characteristics named as bilinear model. The model is built on the standard bilinear hysteretic rules with kinematic strain hardening. The behaviour is varied here throughout the parameters: Yield point load for lead core, Horizontal stiffness (lead core contribution), and horizontal stiffness (elastomer contribution). The nonlinear force deformation behaviour of the rubber-steel bearing is modelled by the bilinear hysteretic model pigeonholed through three parameters specifically: (1) Characteristics strength; (2) Post-elastic stiffness; and (3) Yield displacement (Matsagar, Jangid 2004). An idealised hysteresis for bearing is as shown in Fig $3 b$. The force intercept at zero displacement in a hysteresis, $Q_{d}$, called characteristic strength is allied to yield strength:

$$
Q_{d}=\sigma_{y} A_{p l}
$$

where Yield strength, $\sigma y$, is dependent on the vertical load and lead core confinement.

The post-elastic stiffness:

$$
K_{r}=\frac{G_{\gamma} A_{r}}{T_{r}}
$$

The elastic (or unloading) stiffness (Kilar, Koren 2009) is defined as:

$$
K_{u}=6.5 K_{r}\left(1+\frac{12 A_{p l}}{A_{r}}\right) .
$$

$W$ is the weight of the structure, and can be used to define a bilinear model. The ratio of post-yield stiffness and varies within a small range, $0.08-0.12$ for the lead rubber bearings (LRBs). When the peak displacement of a bilinear model is larger than the yield displacement, the lateral shear force, $F$, effective stiffness, $K_{\text {eff }}$ (secant stiffness) at peak displacement for a bilinear system can be calculated from succeeding equations:

Effective stiffness:

$$
\begin{gathered}
K_{\mathrm{eff}}=\frac{F_{m}}{\Delta} ; \\
F_{m}=Q_{d}+K_{r} \Delta .
\end{gathered}
$$

Effective period:

$$
T_{e}=2 \pi \sqrt{\frac{W}{g \sum K_{\mathrm{eff}}}} .
$$

Equivalent viscous damping:

$$
\beta=\frac{1}{2 \pi}\left(\frac{A_{h}}{K_{\text {eff }} \Delta^{2}}\right)
$$

LRB isolators are strongly nonlinear, i.e. the parameters $K_{\text {eff }}$ and $\beta$ are valid only for design displacement $\Delta_{\max }$. The maximum isolator displacement follows as:

$$
\Delta_{m}=\frac{S_{a} T_{e}^{2}}{4 \pi^{2} B},
$$

where: $S_{a}=$ the spectral acceleration at $T_{e}$.

$F_{m}=F_{\max }=$ Maximum force; $F_{y}=$ Yield Force; $\Delta_{y}=$ Yield Displacement EDC $=$ Energy dissipated per cycle $=A_{h}=$ Area of hysteresis loop.

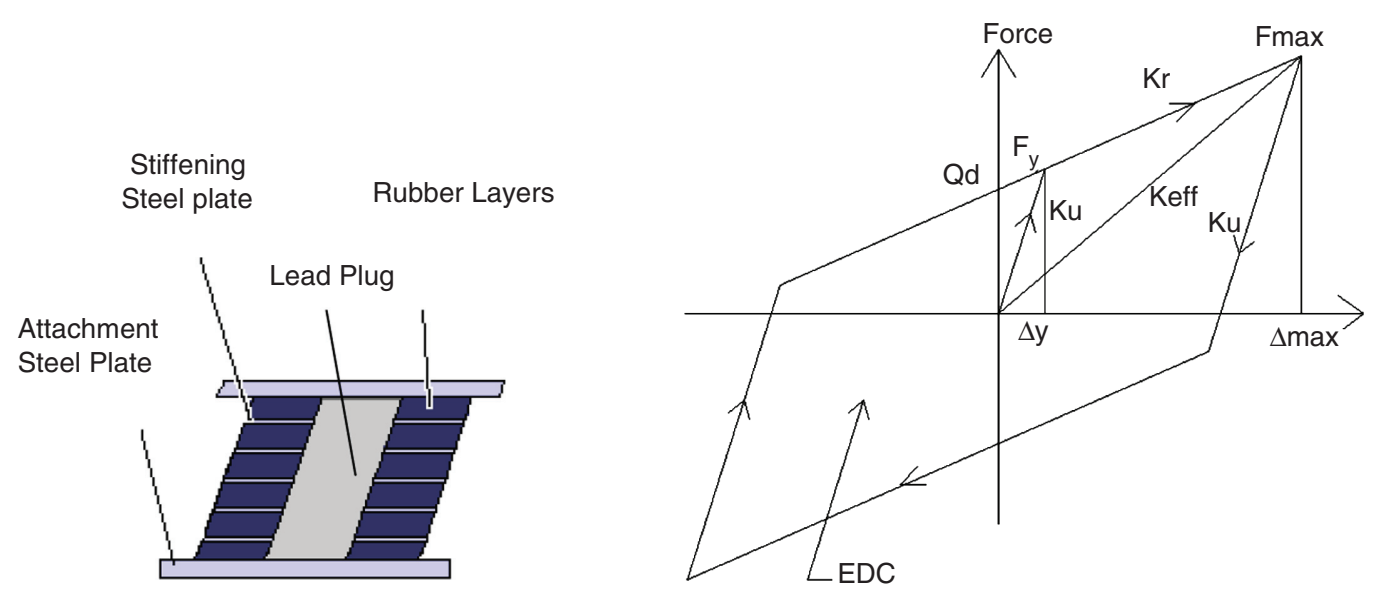

(a)

(b)

Fig. 3. LRB: Deformation pattern (a); idealised Bi-linear hysteretic model (b) 


\subsubsection{HDRB equivalent linear model}

HDRB consists of thin layers of high damping rubber and steel plates fabricated in alternate layers as illustrated in Figure 4a. Low shear modulus of elastomer controls the horizontal stiffness of the bearing. Moreover, steel plates provide high vertical stiffness and preclude bulging of rubber. Horizontal stiffness is not affected by high vertical stiffness for such rubber-steel bearing. Damping in the isolation system is increased by adding extra-fine carbon block, oils or resins, and other proprietary fillers. Parallel action of linear spring and viscous damping are the dominant features of HDRB system. Furthermore, the damping in this bearing model is neither viscous nor hysteretic, but somewhat in between. HDRB executes lower stiffness to get a higher natural period. Equivalent linear elastic viscous damping model has been chosen to configure the HDRB (Fig. 4b). Nonlinear force-deformation characteristic of the rubber-steel bearing is swapped by an equivalent linear model through effective elastic stiffness and effective viscous damping. In this model:

- Instead of $K_{r}$, stiffness is pondered as the effective horizontal stiffness $K_{\text {eff; }}$;

- Damping is considered as effective viscous damping. The equations needed for HDRB modelling follows Eqns (2), (4)-(8). Here the elastic (or unloading) stiffness is defined as:

$$
K_{u}=K_{r} .
$$

\subsection{Lateral static loading}

Linear static analysis, the simplest of all is done as a minimum level of complexity. Seismic lateral load was determined choosing the factors: Z, R, Soil Profile, etc. Furthermore, the lateral load for wind is obtained from the related coefficients. Formula for earthquake and wind analysis has been taken from the international standard local building code BNBC (1993) as follows:

$$
V_{E Q}=Z I C / R,
$$

where: the base shear for earthquake loading is $V_{E Q}$; Seismic zone factor is denoted as $Z ; I=$ Importance factor; $R=$ Response modification factor; $C=1.25 \mathrm{~S} / \mathrm{T}^{2 / 3}$; $S=$ Soil structure interaction; $T=$ structural time period;
$W=$ effective weight of structure.

$$
\left(P_{z}\right)_{W}=C_{G} C_{P} C_{C} C_{I} C_{Z} v_{b}^{2},
$$

where: the design wind pressure at varying height is $\left(P_{z}\right)_{W}$; $C_{C}=$ Conversion coefficient from velocity to pressure, $C_{I}=$ Structure importance coefficient, $C_{Z}=$ Combined height and exposure coefficient, $v_{b}=$ Basic wind speed, $C_{G}=$ Gust coefficient, $C_{p}=$ Pressure coefficient.

\subsection{Equation of motion}

The equations of motion of the superstructure for all base isolation systems can be derived as follows:

$$
[M]\left\{\dot{y}+\ddot{y}_{b}\right\}+[C]\{\dot{y}\}+[K]\{y\}=-[M]\left[T_{g}\right]\left\{\ddot{u}_{g}\right\},
$$

where: $[M],[K]$ and $[C]$ are the mass, damping and stiffness matrices of the superstructure respectively. $\{y\}=$ $\left[y_{x}, y_{y}, y_{z}\right]^{T}$ is the displacement vector at the slab related to the base mass; $\left\{y_{b}\right\}=\left[y_{b x}, y_{b y}, y_{b z}\right]^{T}$ is the vector of base displacements relative to the ground; $\left\{\ddot{u}_{g}\right\}$ is ground acceleration vector and $\left[T_{g}\right]$ is earthquake influence coefficient matrix.

\subsection{Dynamic solution}

Dynamic frequency domain analysis is required for systems with non-proportional damping, hysteric and frequency dependent properties. The approach offers computational pluses in prediction of displacements, velocity and acceleration of ground subjected to structural systems. Equations of motion for linear analysis are transformed into normal coordinate system. Applying the normal coordinate transformation, the decoupled equation of motion for individual modes leads to:

$$
\begin{aligned}
& {\left[M_{n}\right]\left\{\dot{y}(t)_{n}+\ddot{y}_{b}(t)_{n}\right\}+\left[C_{n}\right]\left\{\dot{y}(t)_{n}\right\}+\left[K_{n}\right]\left\{y(t)_{n}\right\}=} \\
& \quad-[M]\left[T_{g}\right]\left\{\ddot{u}(t)_{g}\right\} .
\end{aligned}
$$

The solution can be carried out individually for each decoupled modal equation as the succeeding Eqn (14). $\zeta$ is modal damping ratio and $\omega_{n}$ is un-damped natural frequency:

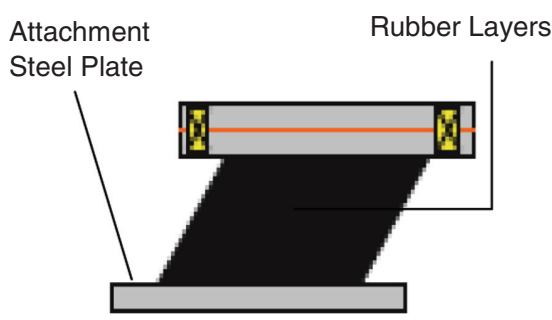

a)

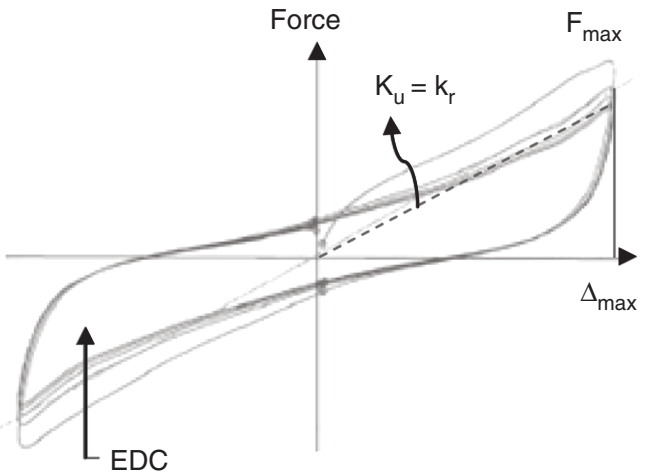

b)

Fig. 4. HDRB: (a) Deformation pattern; (b) Equivalent linear hysteretic model 


$$
\ddot{y}(t)_{n}+2 \zeta \omega_{n} \dot{y}(t)_{n}+\omega_{n}^{2} y(t)_{n}=-\ddot{u}(t)_{g} .
$$

Total acceleration of the unit mass in single degree-offreedom system, governed by Eqn (14), is given by:

$$
\ddot{u}(t)_{T}=\ddot{y}(t)+\ddot{u}(t)_{g} .
$$

Eqn (14) can be solved for $y(t)$ and substituting the term into Eqn (15) yields:

$$
\ddot{u}(t)_{T}=-2 \zeta \omega \dot{y}(t)-\omega^{2} y(t) .
$$

Maximum modal displacement can be obtained for a typical mode $n$ with period $T_{n}$ and corresponding spectrum response value $S\left(\omega_{n}\right)$. The maximum modal response associated with period $T_{n}$ is calculated by Eqn (17) and maximum modal displacement response by Eqn (18).

$$
\begin{gathered}
y\left(T_{n}\right)_{\mathrm{MAX}}=S\left(\omega_{n}\right) / \omega^{2} ; \\
u_{n}=y\left(T_{n}\right)_{\mathrm{MAX}} \Phi_{n} .
\end{gathered}
$$

The frequency domain analysis has been performed using aforementioned mode superposition. These modal values were combined following complete quadratic combination (CQC) technique. Furthermore, the directional combination was done by SRSS method.

\section{Numerical investigation}

The 10 storey building to isolate, located in Dhaka at seismic zone 2 , is considered for this study. It is a moment resisting frame structure consisting of 4 spacing@ $7.62 \mathrm{~m} \mathrm{c} / \mathrm{c}$ in both direction (Fig. 1). Supposed parameters are: $\mathrm{f}^{\prime} \mathrm{c}=28 \mathrm{MPa}$, fy $=414 \mathrm{MPa}$, dead load (excluding selfweight $)=4.8 \mathrm{KPa}$, Live load $=2.4 \mathrm{KPa}$, slab thickness $=$ $150 \mathrm{~mm}$, Exterior corner columns are all $750 \mathrm{~mm} \times 750 \mathrm{~mm}$, Exterior middle columns are all $950 \mathrm{~mm} \times 950 \mathrm{~mm}$, Interior columns are all $1000 \mathrm{~mm} \times 1000 \mathrm{~mm}$. The rubber-steel bearings are installed at the base level of each corresponding column.

The designs of isolator were done based on the design requirements, using developed programme as mentioned in preceding section. Total Seismic load and the governed vertical loads on columns have been obtained following the linear static analysis. The plan size and rubber layer configuration have been duly incorporated for both the isolators along with the lead core size especially for LRB. The designs for LRB and HDRB have been exemplified in subsequent lesson. Seismic loads on the bearings obtained from the dynamic analysis of isolated based building are used to check the isolators for roll-out condition. HDRB and LRB have been assigned at interior and exterior columns base respectively assuming their suitability at respective link position.

For equivalent static analysis of the conventional fixed based building, procedures described at BNBC are adopted. For isolated building, response modification factor has been taken as $\mathrm{R}_{\mathrm{I}}=2.0$ (Kelly et al. 2006) and importance coefficient has also been chosen as 1.0 as per occupancy category (Kelly 2001). Free vibration analysis has been carried out to evaluate the time period, frequency and circular frequency at different mode shape.

The earthquake data has been chosen as the Dhaka EQ time history developed for nearby seismic occurred Islam et al. (2011b). The Time history data for Dhaka earthquake has been shown in Figure 5. Dynamic analyses for frequency domain have been performed first for fixed base structure to comprehend the behaviours. Then after linking them with the properties of isolators at the respective column base, dynamic analyses were again performed. The analysis follows the usual procedure where springs having effective stiffness of the isolators are modelled to connect the base level of the structure to the ground. For the analysis, 100\% response spectrum was applied to $\mathrm{x}$-direction and $30 \%$ of the spectrum (Win 2008) was applied to orthogonal y-direction of the structure.

\section{Results and discussion}

\subsection{Static analysis}

The linear static analysis of the conventional fixed based building adopting the procedure described at BNBC executes the results shown in Table 1 . Here, the design base shear for earthquake loading is greater than that for wind loading. Lateral load due to wind is about $3 \%$ of the weight of the building. Maximum top storey displacement has larger value for seismic loading compared to the lateral wind action. However, at the base of the conventional structure, the structure experiences no displacement as the building is fixed at these supports. Apart from these, the bearing itself moves at a significant displacement in case of isolated based building. Therefore, though top storey displacements are larger for base isolated structure, total structural drifts show small values of horizontal movements. In both cases, seismic loading governs. Hence, mitigation of later seismic effect requires that isolation device is to be incorporated aimed at dissipating seismic energy.

\subsection{Structural feasibility for incorporating Isolator}

The structural time period is shifted to 0.91 second for isolated building from fixed structure time period 2.85 second. The rating of the parameter suits the criteria for most suitable value, i.e. $\leq 1.0$ second (Kelly 2001; Kelly et al. 2006) for isolating. In addition, the site allows horizontal displacements in amount of $200 \mathrm{~mm}$ or more at the base level and lateral load due to wind is lesser than $10 \%$ of the weight of the building as requirement (Deb 2004). Seismic excitation is the governing loading. Therefore, isolator can be incorporated at the base of the structure as an alternate adoption against conventional fixed based design.

\subsubsection{Isolator properties}

The properties used to model the bearings as spring were taken in suitable format for the SAP programme. Required parameters of the hysteresis loops are determined by the developed programme DESBEA providing the maximum column loads linking on the respective isolators. Circular bearing has been designed with diameter $800 \mathrm{~mm}$ and 950 $\mathrm{mm}$ for LRB and HDRB respectively. A number of 16 


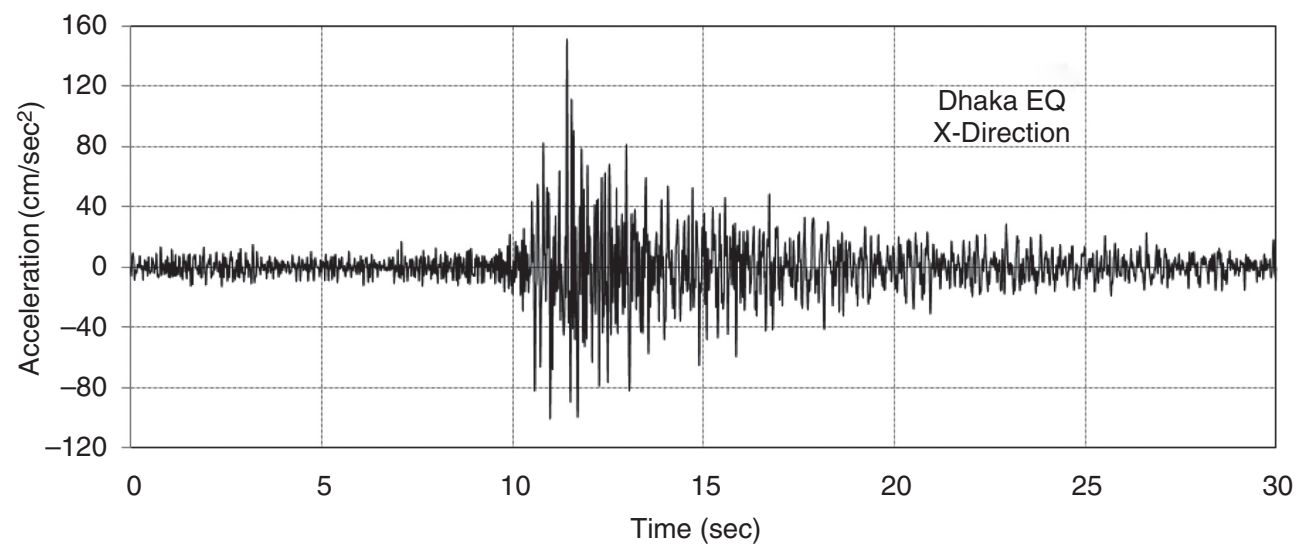

a) X-direction

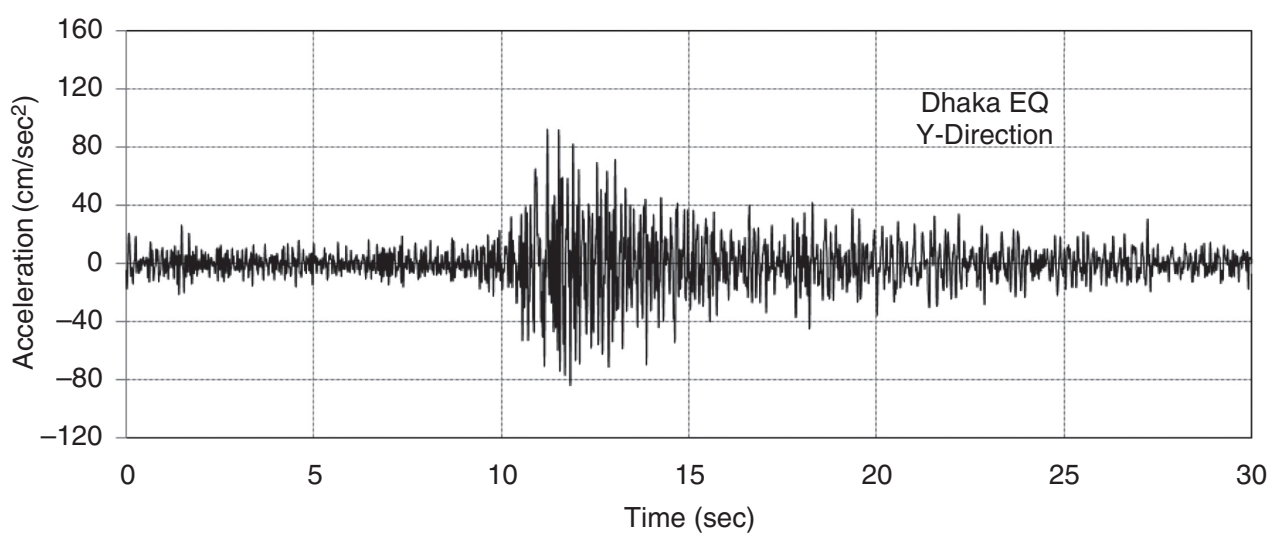

b) Y-direction

Fig. 5. Dhaka EQ Time History in (a) X-direction and (b) Y-direction

Table 1. Static analysis results (fixed base building)

\begin{tabular}{ll}
\hline Parameter & \multicolumn{1}{c}{ Rating } \\
\hline Maximum Base Shear (EQ loading) & $3936 \mathrm{KN}$ \\
Maximum Base Shear (Wind loading) & $2829 \mathrm{KN}$ \\
Maximum Base Moment (EQ loading) & $89523 \mathrm{KN}-\mathrm{m}$ \\
Maximum Base Moment (Wind loading) & $48547 \mathrm{KN}-\mathrm{m}$ \\
Maximum Top storey Displacement (EQ loading) & $14.1 \mathrm{~mm}$ \\
Maximum Top storey Displacement & $6.6 \mathrm{~mm}$ \\
(Wind loading) & \\
Base Displacement (EQ and Wind loading) & 0 \\
Total weight of Building & $127754 \mathrm{KN}$ \\
Governing Axial load on Interior Column & $7215 \mathrm{KN}$ \\
Governing Axial load on Exterior Column & $4546 \mathrm{KN}$ \\
\hline
\end{tabular}

layers have been maintained using 10 -mm thick rubber element. In addition 40-mm thick steel plated at both the sides of bearing formed $240-\mathrm{mm}$ height isolator for both cases. The corresponding stiffness's, damping and postyielding ratio have been duly designed and incorporated in SAP isolator modelling.

\subsubsection{Isolator performance}

Linear static and nonlinear dynamic analyses of the building structure with isolator show the highest analysed values of the mentioned structural parameters as in Table 2. All the values of structural maximum (top) displacements lie below the isolator design displacement $292.61 \mathrm{~mm}$ for MCE level of earthquake. The isolation bearing status is checked by the factors of safety as F.S. exceeding 1.0 indicates satisfactory performance. The performance of the isolated structure has been evaluated for the design basis earthquake (DBE). To check the performance against Maximum credible earthquake (MCE), the seismic coefficients $\mathrm{C}_{\mathrm{AM}}$ and $\mathrm{C}_{\mathrm{VM}}$ for $\mathrm{Z}=0.15$ and soil profile $\mathrm{S} 3$ are considered as 0.35 and 0.55 , respectively. The isolator properties and both assessments for earthquake levels are satisfactory in good agreement.

\subsection{Free vibration analysis}

The free vibration behaviour of structure is essentially used to analyse the results obtained by dynamic analysis. For assessment of natural frequencies, the free vibration analysis has been performed for both fixed based and isolated based buildings. Time period, frequency and circular frequency for 15 modes are shown in Tables 3 and 4 . In first mode, the time period for fixed building is 
Table 2. Static analysis results (isolated base building)

\begin{tabular}{|c|c|c|c|}
\hline Parameter & $\begin{array}{c}\text { Top storey } \\
\text { displacement } \\
(\mathrm{mm})\end{array}$ & $\begin{array}{c}\text { Isolator } \\
\text { displacement } \\
(\mathrm{mm})\end{array}$ & $\begin{array}{l}\text { Total } \\
\text { structure drift } \\
(\mathrm{mm})\end{array}$ \\
\hline $\begin{array}{l}\text { Displacement } \\
\text { (EQ Loading) }\end{array}$ & 88.5 & 72.8 & 15.7 \\
\hline $\begin{array}{l}\text { Displacement } \\
\text { (Wind Loading) }\end{array}$ & 53.8 & 52.2 & 1.6 \\
\hline \multicolumn{4}{|c|}{ Table 3. Free vibration analysis result (fixed building) } \\
\hline & Period & Frequency & $\begin{array}{l}\text { Circular } \\
\text { frequency }\end{array}$ \\
\hline Mode no & $\mathrm{Sec}$ & Cyc/sec & $\mathrm{Rad} / \mathrm{sec}$ \\
\hline 1 & 0.913201 & 1.095 & 6.8804 \\
\hline 2 & 0.913201 & 1.095 & 6.8804 \\
\hline 3 & 0.820971 & 1.2181 & 7.6534 \\
\hline 4 & 0.305778 & 3.2703 & 20.548 \\
\hline 5 & 0.305778 & 3.2703 & 20.548 \\
\hline 6 & 0.277169 & 3.6079 & 22.669 \\
\hline 7 & 0.169141 & 5.9122 & 37.148 \\
\hline 8 & 0.169141 & 5.9122 & 37.148 \\
\hline 9 & 0.156279 & 6.3988 & 40.205 \\
\hline 10 & 0.112683 & 8.8745 & 55.76 \\
\hline 11 & 0.109486 & 9.1335 & 57.388 \\
\hline 12 & 0.109486 & 9.1335 & 57.388 \\
\hline 13 & 0.106621 & 9.379 & 58.93 \\
\hline 14 & 0.106621 & 9.379 & 58.93 \\
\hline 15 & 0.100209 & 9.9791 & 62.701 \\
\hline
\end{tabular}

$0.913 \mathrm{sec}$ which increases up to more than three times for isolated building. But the rate of increment reduces for higher modes up to $20 \%$.

Tables 3 and 4 summarise main issues of the fixed and isolated buildings modal analysis. According to the modal response view point, the supreme consequence of the base isolation through rubber-steel bearings is epitomised by momentous frequency shift of main horizontal modes. In traditional fixed based structure, the frequency at the first mode comes as $1.095 \mathrm{~Hz}$. Apart from this, the frequency associated with the building on the modelled bearings is far lower than the analogous frequency for conventional fixed based foundation. The frequency is shifted to $0.35 \mathrm{~Hz}$ that is in the target range $(0.3-0.5 \mathrm{~Hz})$ (Micheli et al. 2004). It is also observed that the first global modes for the conventional fixed based foundations are mainly rocking modes. However, in the case of seismic isolation, they are related to horizontal pure translation movements. Furthermore, the shift of natural vibration period of an isolated system points out that
Table 4. Free vibration analysis result (isolated building)

\begin{tabular}{lccc}
\hline & Period & Frequency & $\begin{array}{c}\text { Circular } \\
\text { frequency }\end{array}$ \\
\cline { 2 - 4 } Mode no & Sec & Cyc/sec & Rad/sec \\
\hline 1 & 2.847 & 0.351 & 2.207 \\
2 & 2.847 & 0.351 & 2.207 \\
3 & 2.837 & 0.353 & 2.215 \\
4 & 0.478 & 2.090 & 13.135 \\
5 & 0.478 & 2.090 & 13.135 \\
6 & 0.416 & 2.407 & 15.121 \\
7 & 0.214 & 4.680 & 29.406 \\
8 & 0.214 & 4.680 & 29.406 \\
9 & 0.194 & 5.151 & 32.365 \\
10 & 0.169 & 5.913 & 37.153 \\
11 & 0.160 & 6.258 & 39.321 \\
12 & 0.160 & 6.258 & 39.321 \\
13 & 0.145 & 6.875 & 43.194 \\
14 & 0.141 & 7.084 & 44.511 \\
15 & 0.135 & 7.383 & 46.387 \\
\hline
\end{tabular}

rubber-steel bearings provide more flexible structural system as portrayed in the shifted effective frequency.

\subsection{Frequency domain analysis}

Dynamic analyses for frequency domain have been performed for fixed base structure to explore the behaviours individually. The responses from the fixed based building are pointed out in Table 5. The structure with isolators is also analysed once more for frequency domain as the frequency domain analysis governs among the types of structural analyses. The evidences of Tables 6 and 7 have been attained from dynamic analysis of isolated building. It is noted that the response spectrum plays vital role in dynamic result as it considers the peak values of motion responses.

Table 5. Dynamic analysis results (fixed buildings)

\begin{tabular}{lc}
\hline Parameter & $\begin{array}{c}\text { Frequency } \\
\text { domain analysis }\end{array}$ \\
\hline Maximum Base Shear (KN) in X-direction & 2778 \\
Maximum Base Shear (KN) in Y-direction & 834 \\
Maximum Base Moment (KN-m) in X-direction & 17897 \\
Maximum Base Moment (KN-m) in Y-direction & 59631 \\
Top storey Displacement in X-direction (mm) & 8.4 \\
Top storey Displacement in Y-direction (mm) & 4.1 \\
\hline
\end{tabular}


Table 6. Displacement output in dynamic analysis (isolated building)

\begin{tabular}{lcc}
\hline & $\begin{array}{c}\text { Isolator } \\
\text { displacement } \\
(\mathrm{mm})\end{array}$ & $\begin{array}{c}\text { Total } \\
\text { structure } \\
\text { drift }(\mathrm{mm})\end{array}$ \\
\hline X-direction (Static Analysis) & 72.8 & 15.7 \\
Y-direction (Static Analysis) & 72.8 & 15.7 \\
X-direction (Frequency Domain & 17.5 & 3.7 \\
Analysis) & & \\
$\begin{array}{l}\text { Y-direction (Frequency Domain } \\
\text { Analysis) }\end{array}$ & 4.9 & 1.1 \\
\hline
\end{tabular}

Table 7. Base shear and base moment in dynamic analysis (isolated building)

\begin{tabular}{lc}
\hline Parameter & $\begin{array}{c}\text { Frequency } \\
\text { domain } \\
\text { analysis }\end{array}$ \\
\hline Maximum Base Shear (KN) in X-direction & 1106 \\
Maximum Base Shear (KN) in Y-direction & 311 \\
Maximum Base Moment (KN-m) in X-direction & 5618 \\
Maximum Base Moment (KN-m) in Y-direction & 20001 \\
\hline
\end{tabular}

\subsubsection{Floor acceleration spectra}

Prime upshot of seismic base isolation on structural base is that the isolated structure experiences momentous amount of reduction in floor accelerations (Figs 6-9 and Figs 12-15). At this juncture, the floor acceleration response spectra are found out at top storey and base of the structure for both non-isolated and isolated foundations due to seismic horizontal excitations. The illustrations show that the spectral horizontal accelerations reduce in a drastic manner for flexible structure. The phenomenon is desirable due to the low frequencies witnessed in the building modes compared to the conforming accelerations for non-isolated building. The comparative statistics of modal accelerations for fixed based building and isolated based building has been illustrated in Tables 8 and 9, respectively.

The lessening of peak accelerations in response spectra at the support level is up to $50 \%$ for isolated buildings than those of fixed building. At the top floor, the acceleration reduces around five times while isolators are incorporated. Soft to medium stiff soil condition has been considered for the mentioned assessments; however, similar suppositions could be drawn for any other soil type as well.

\subsubsection{Displacement spectra}

At the foundation level of the building, maximum horizontal displacement was around $67.2 \mathrm{~mm}$ for isolated case. Apart from this, for orthodox foundation, the analogous maximum displacement was found to be $11.5 \mathrm{~mm}$. For fixed building, the joint at support is fully rigid and there is no lateral movement in the joint at base level. But in case of isolation, the isolator itself moves laterally. So, total structural drift is lesser than that of fixed based case.

The displacement response spectra show that the maximum peak value at top storey increases up to $40 \%$ for isolated buildings than those of fixed building. In addition, the bearings move horizontally at a reasonable amount at support level, tending to shift the full superstructure. Relative difference between the top storey and support level displacements confirms that the total structural drift is nominal. The agreeing response spectra are shown in Figures 10, 11, 16-19. The peculiar behaviour is that shifting the structure through rubber-steel bearing offers the structure's deformed shape as almost consistently vertical.

In case of incorporating rubber-steel bearing, the displacements of both the superstructure and the isolation device upturn as superstructure becomes more flexible.

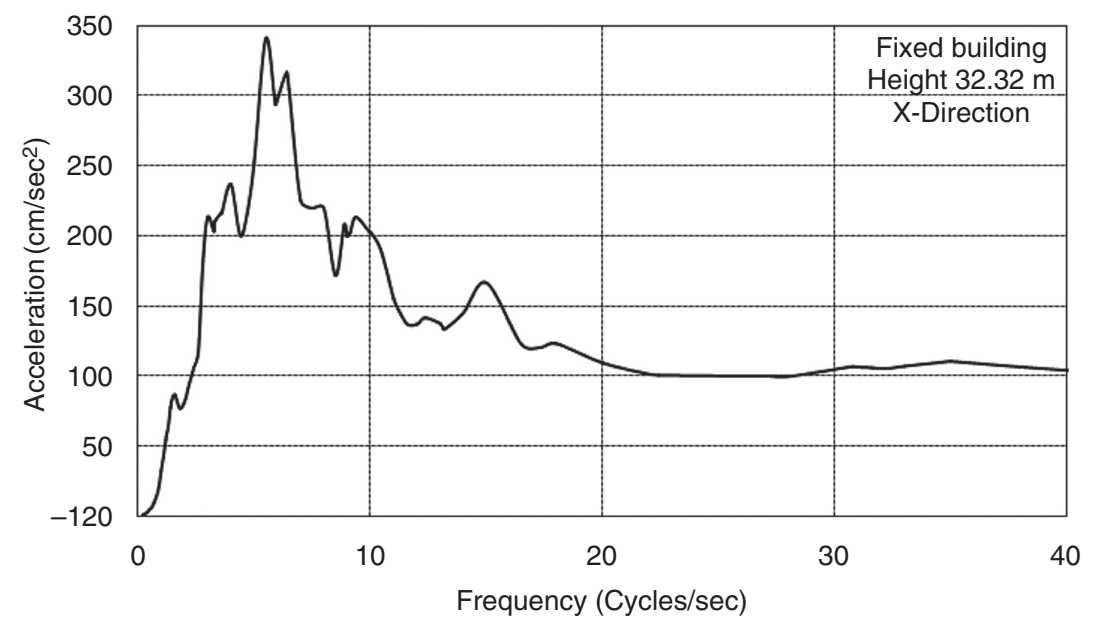

Fig. 6. Spectral Acceleration in X-direction (fixed building) 


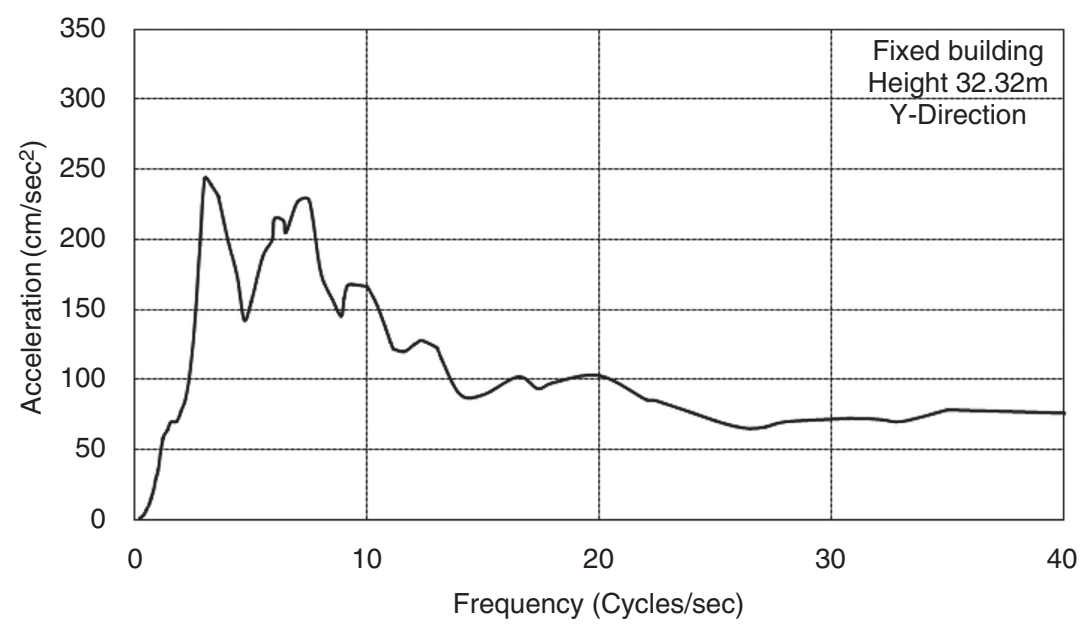

Fig. 7. Spectral Acceleration in Y-direction (fixed building)

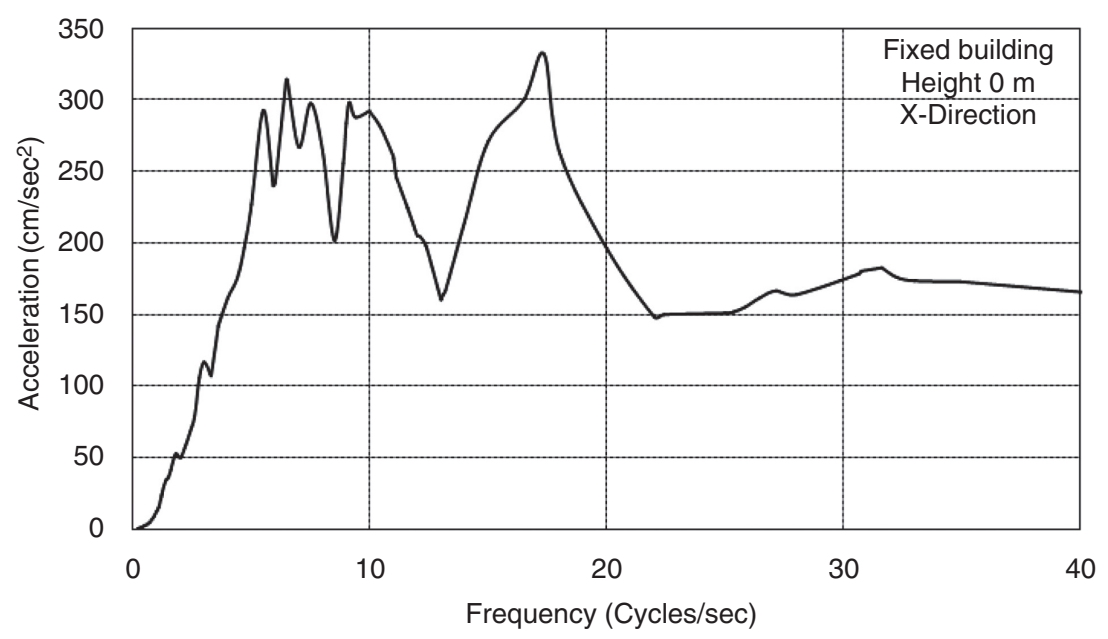

Fig. 8. Spectral Acceleration in X-direction (fixed building)

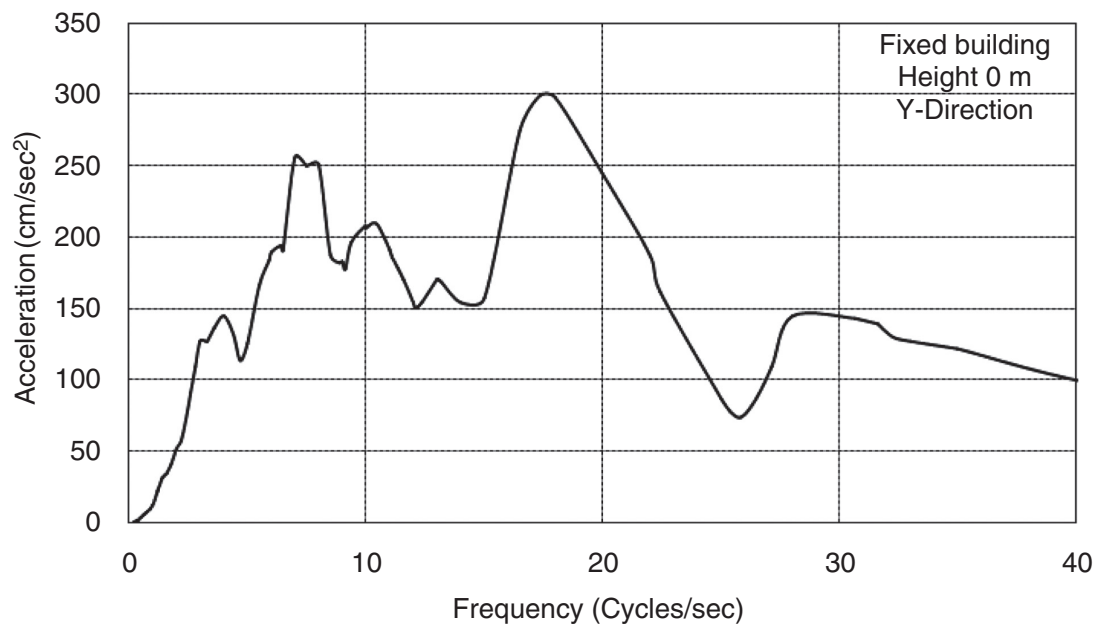

Fig. 9. Spectral Acceleration in Y-direction (fixed building) 
Table 8. Frequency domain modal acceleration for varying period (fixed building)

\begin{tabular}{lcc}
\hline Period $(\mathrm{sec})$ & $\begin{array}{c}\text { Acceleration } \\
\text { X-direction }\left(\mathrm{cm} / \mathrm{sec}^{2}\right)\end{array}$ & $\begin{array}{c}\text { Acceleration } \\
\text { Y-direction }\left(\mathrm{cm} / \mathrm{sec}^{2}\right)\end{array}$ \\
\hline 0.913201 & 29.77 & 8.935 \\
0.913201 & 29.77 & 8.935 \\
0.820971 & 33.044 & 9.917 \\
0.305778 & 46.06 & 13.824 \\
0.305778 & 46.06 & 13.824 \\
0.277169 & 46.06 & 13.824 \\
0.169141 & 46.06 & 13.824 \\
0.169141 & 46.06 & 13.824 \\
0.156279 & 46.06 & 13.824 \\
0.112683 & 46.06 & 13.824 \\
0.109486 & 45.87 & 13.767 \\
0.109486 & 45.87 & 13.767 \\
0.106621 & 44.814 & 13.45 \\
0.106621 & 44.814 & 13.45 \\
0.100209 & 42.449 & 12.74 \\
\hline
\end{tabular}

Table 9. Frequency domain modal acceleration for varying period (isolated building)

\begin{tabular}{lcc}
\hline Period $(\mathrm{sec})$ & $\begin{array}{c}\text { Acceleration } \\
\text { X-direction }\left(\mathrm{cm} / \mathrm{sec}^{2}\right)\end{array}$ & $\begin{array}{c}\text { Acceleration } \\
\text { Y-direction }\left(\mathrm{cm} / \mathrm{sec}^{2}\right)\end{array}$ \\
\hline 2.847212 & 9.768 & 2.932 \\
2.847212 & 9.138 & 2.743 \\
2.836714 & 9.285 & 2.787 \\
0.478372 & 46.05 & 13.821 \\
0.478372 & 44.588 & 13.382 \\
0.41553 & 45.13 & 13.545 \\
0.213669 & 46.059 & 13.823 \\
0.213669 & 44.803 & 13.446 \\
0.194135 & 45.23 & 13.575 \\
0.169118 & 45.96 & 13.794 \\
0.15979 & 45.931 & 13.785 \\
0.15979 & 45.834 & 13.756 \\
0.145465 & 45.93 & 13.785 \\
0.14116 & 45.961 & 13.794 \\
0.135452 & 45.864 & 13.765 \\
\hline
\end{tabular}

Such a fashion is factual for static, free vibration as well as frequency domain analysis.

\subsubsection{Frequency of peak responses}

The ranges of occurrence of peak responses have been evaluated for both the fixed structure and the building isolated with rubber-steel bearing. The assessment shows good agreement with isolation strategy and benefits for seismic retrofit. In the floor acceleration spectrum, the peaks of spectral accelerations remain in the range $3-11 \mathrm{~Hz}$ for fixed and isolated building at top (Figs 6-7 and Figs 12-13). But at the support level of the building structure, the peaks occur in the range $6-19 \mathrm{~Hz}$ for the isolated and non-isolated buildings (Figs 8-9 and Figs 14-15).

Furthermore, in displacement spectrum, the peaks fall the range $0.5-3.5 \mathrm{~Hz}$ for fixed building at top floor of the structure (Figs 10-11). However, for isolated building, the peaks lie in the range $0.2-0.5 \mathrm{~Hz}$ at the top (Figs 16-17) and at base 0.2-2.4 Hz (Figs 18-19).

The main isolation frequency is found to be lowered and higher rigid-body displacements are taken into account in the design of building. A reliable base isolation is obtained by adequate uses of bearings. Thus, the base excitation periods of the order of $3 \mathrm{~s}$ are offered. An actual isolation frequency of the order of $0.25 \mathrm{~Hz}$ ( $4 \mathrm{~s}$ period), below the usual range $0.3-0.5 \mathrm{~Hz}$, is indeed maintained which ensures moderate floor accelerations alongside satisfactory rigid body displacements.

\subsubsection{Base shear and base moment}

The base shears and overturning base moments in each direction are decreased for isolated structure compared to the fixed building. Such decrement ensures momentous structural savings and subsequently predicts economic benefits. Table 7 illustrates these maximum responses at base level of the isolated based building against the response behaviours for fixed base case mentioned at Table 5. It is observed that in directions, shear force and overturning moment at structural bases offer reasonable lessening of their peak values.

Furthermore, maximum governing seismic responses for fixed and isolated based building have been weighed in Table 10. The statistics show that the base moment decreases up to around $70 \%$. In addition, about $40 \%$ of overturning moment lessens. This decrement of structural base responses ensures that the bearing provides additional flexibility to the structures. Therefore, the design structural parameters consequently confirm significant structural savings.

\subsection{Influence of bearing models in simulation}

The developed models of the bearings exhibit authentic comportment of the isolating elements and their effect on the structural excursions. The selected simulation includes the exact modelling and analysis in a consistent manner. The dynamic analysis in frequency domain is found to be efficient, requiring very less time, but it offers precise solution. Incorporation of rubber-steel bearing provides transitional movements of the superstructure at the support level. Additional flexibility is therefore well achieved, and the hyperbolic deflection behaviour changes muscularly. Structural and economic savings are accomplished accordingly. Therefore, in medium risk seismic vulnerable area, the rubber-steel bearing isolation system can be beneficially incorporated. 


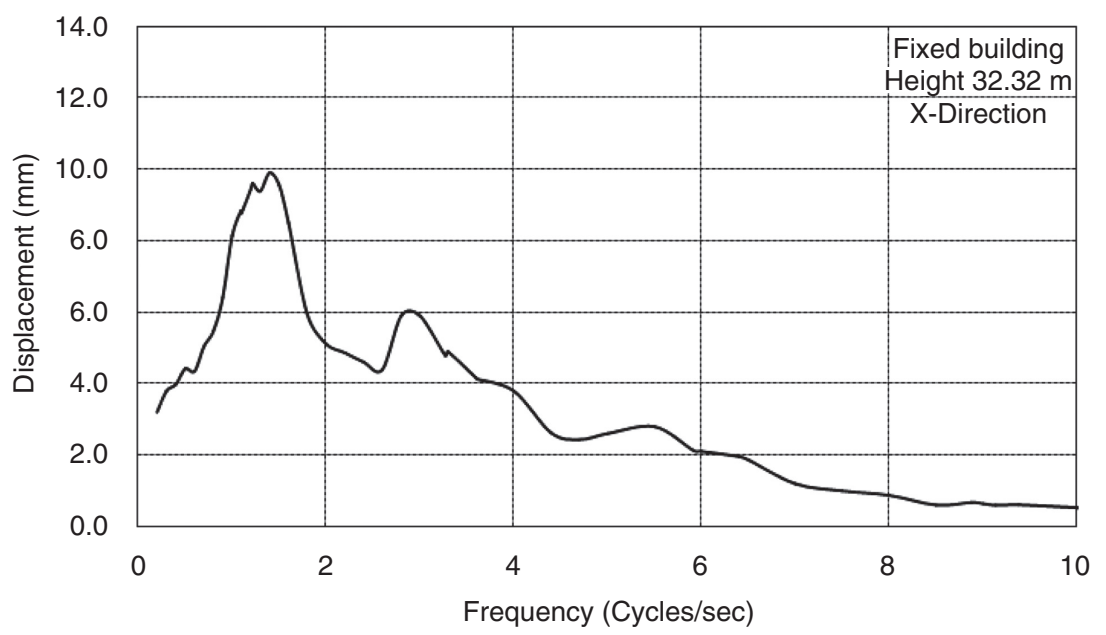

Fig. 10. Spectral Displacement in X-direction (fixed building)

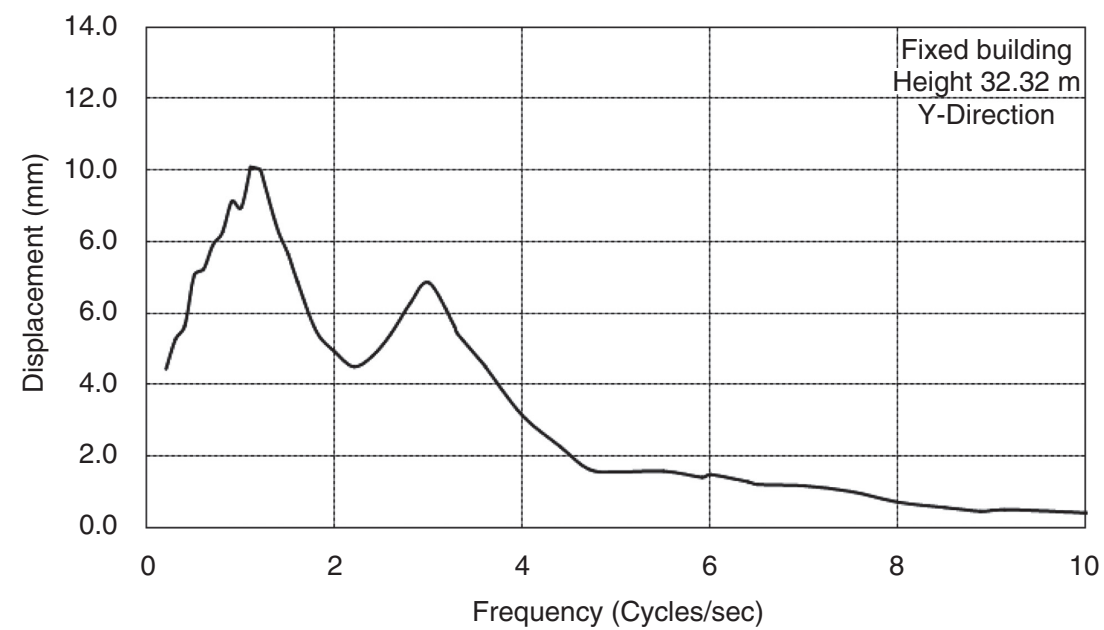

Fig. 11. Spectral Displacement in Y-direction (fixed building)

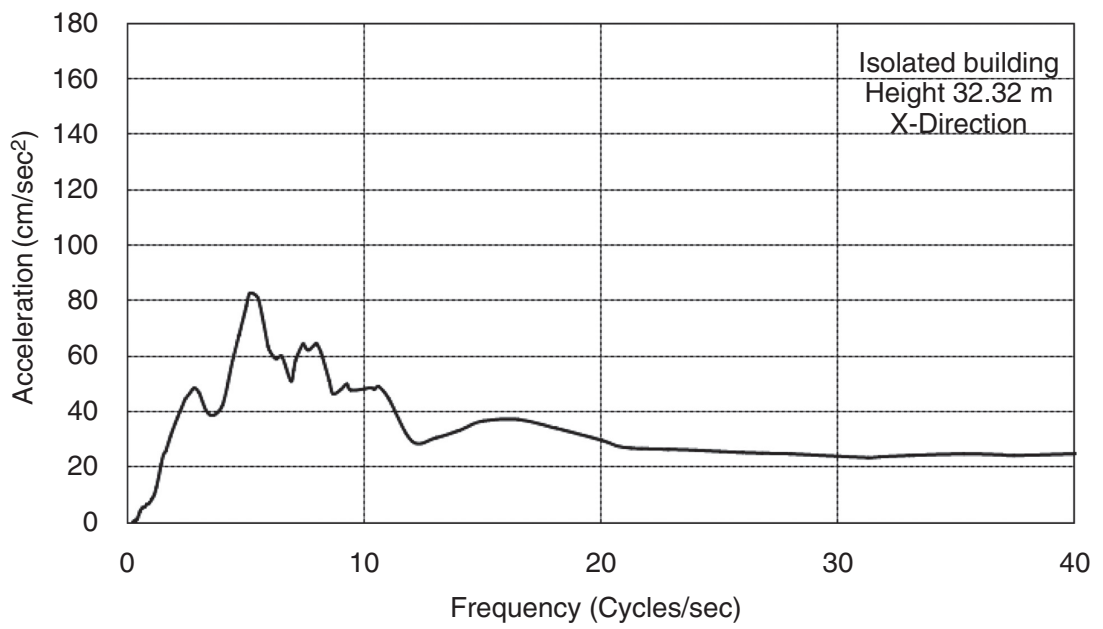

Fig. 12. Spectral Acceleration in X-direction (isolated building) 


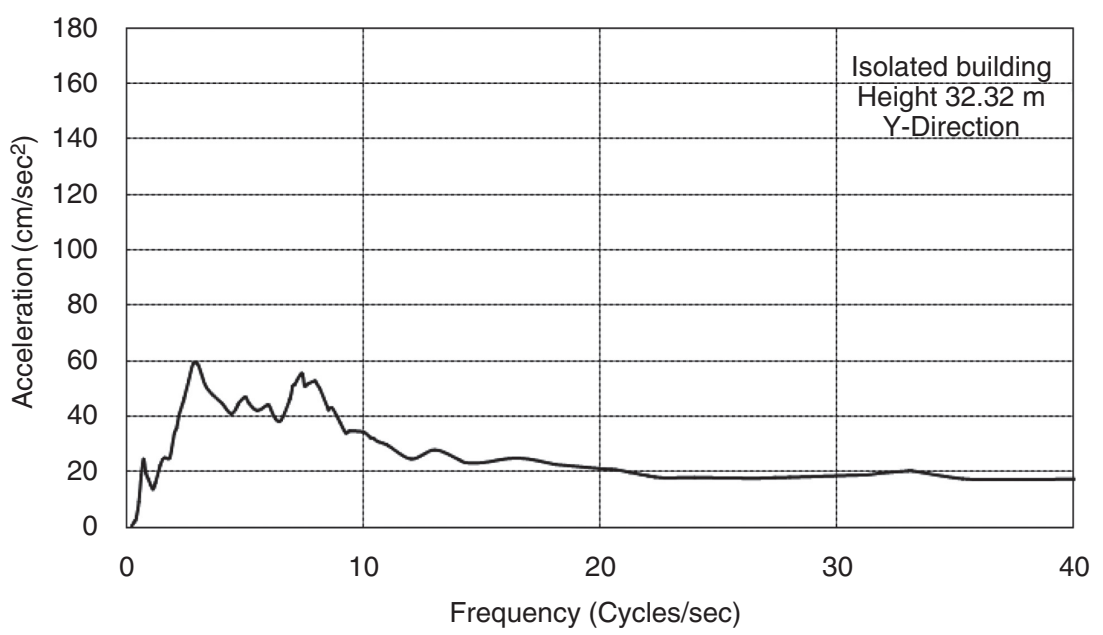

Fig. 13. Spectral Acceleration in Y-direction (isolated building)

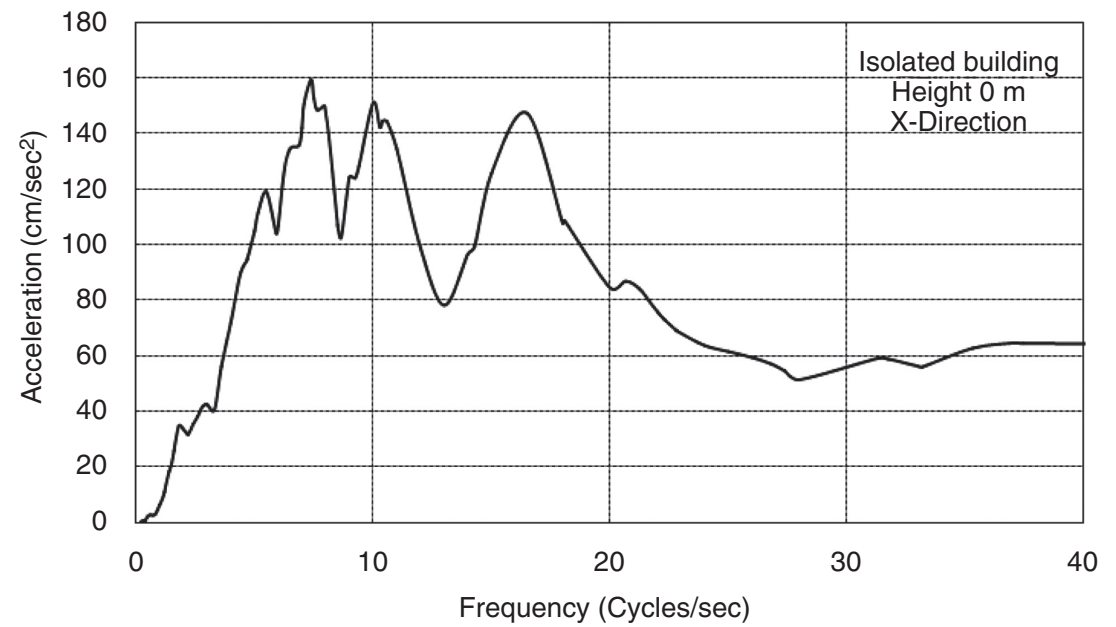

Fig. 14. Spectral Acceleration in X-direction (isolated building)

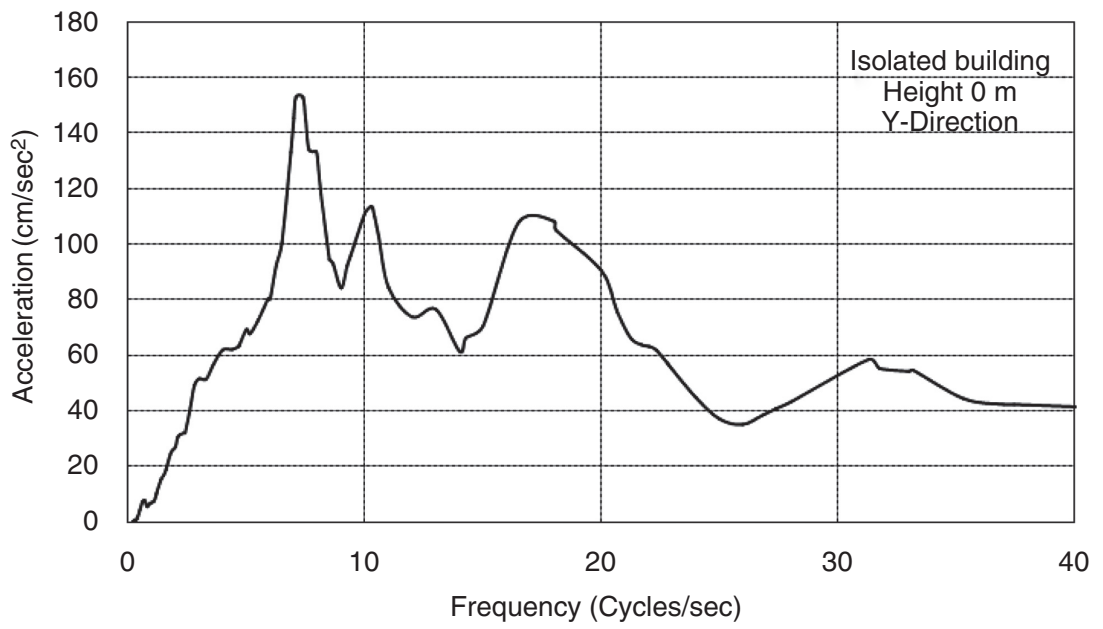

Fig. 15. Spectral Acceleration in Y-direction (isolated building) 


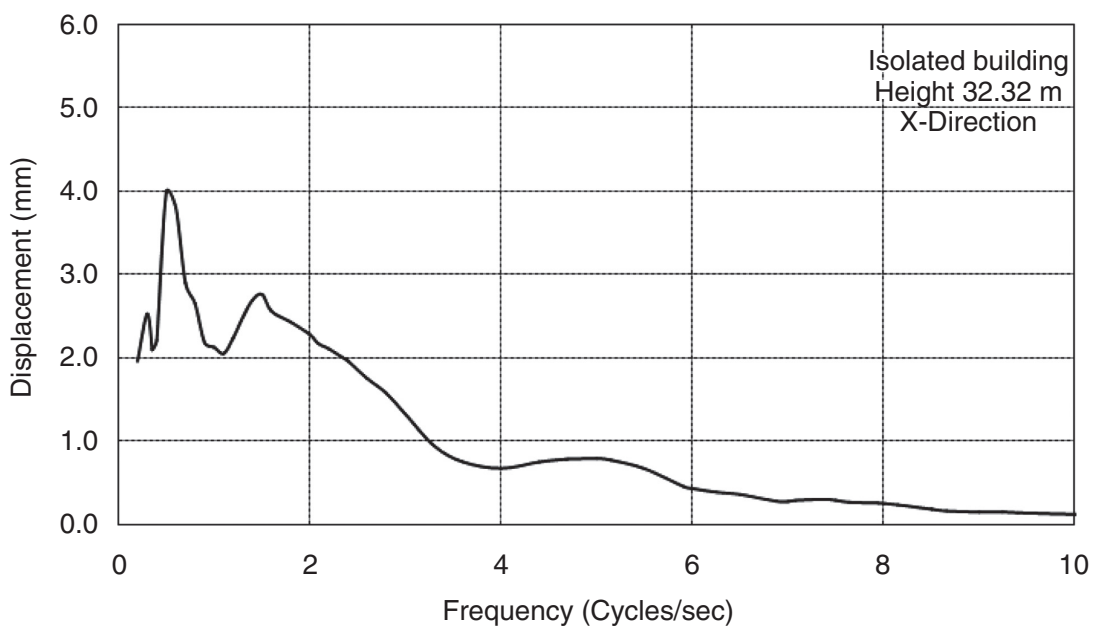

Fig. 16. Spectral Displacement in X-direction (isolated building)

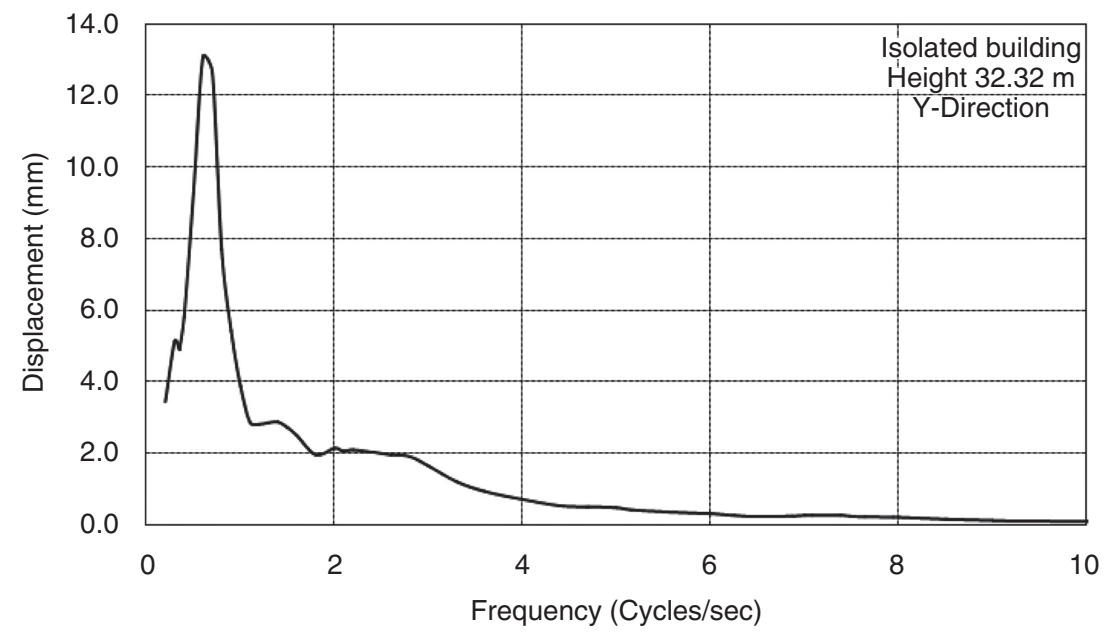

Fig. 17. Spectral Displacement in Y-direction (isolated building)

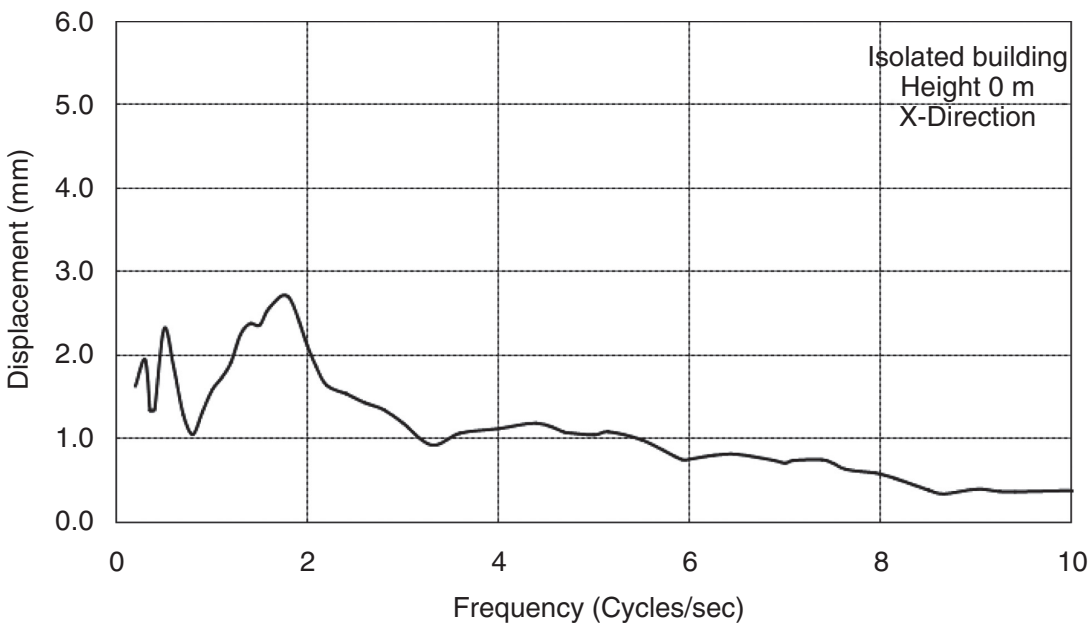

Fig. 18. Spectral Displacement in X-direction (isolated building) 


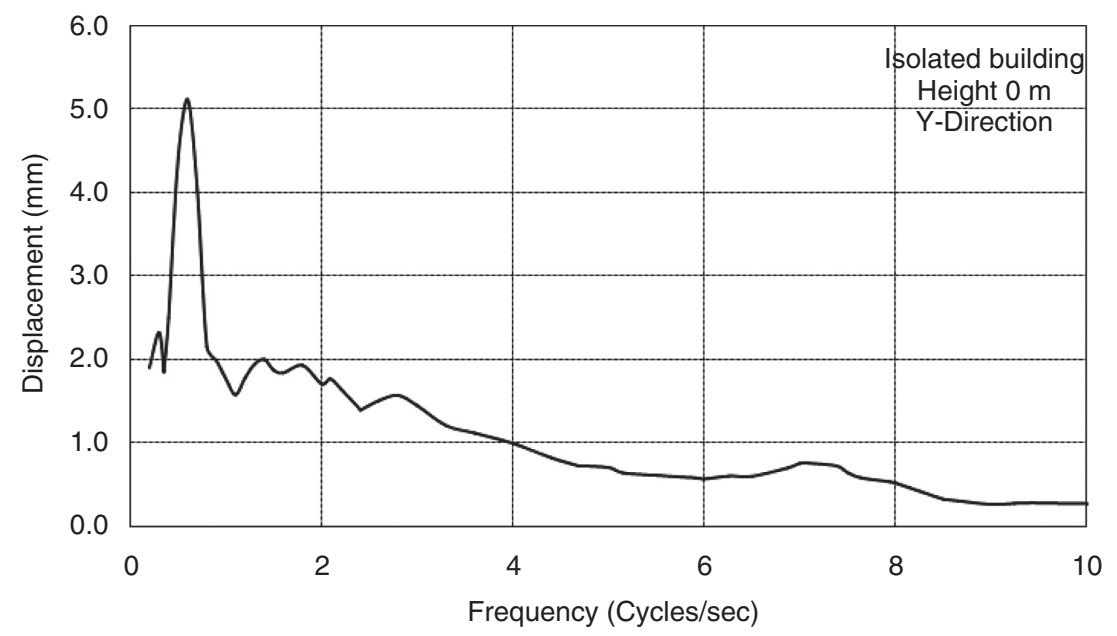

Fig. 19. Spectral Displacement in Y-direction (isolated building)

Table 10. Maximum (governing) seismic responses of fixed and base isolated structure

\begin{tabular}{|c|c|c|c|c|}
\hline \multirow[b]{2}{*}{$\begin{array}{l}\text { Building } \\
\text { type }\end{array}$} & \multicolumn{2}{|c|}{ Displacement (mm) } & \multirow[b]{2}{*}{$\begin{array}{c}\text { Base } \\
\text { shear }(\mathrm{KN})\end{array}$} & \multirow{2}{*}{$\begin{array}{c}\text { Overturning } \\
\text { moment } \\
(\mathrm{KN}-\mathrm{m})\end{array}$} \\
\hline & Top & $\begin{array}{l}\text { Base/ } \\
\text { Isolator }\end{array}$ & & \\
\hline Fixed & 11.5 & 0 & 3936 & 89523 \\
\hline Base Isolated & 88.5 & 72.8 & 1106 & 59631 \\
\hline
\end{tabular}

\section{Conclusion remarks}

The dynamic analysis in frequency domain is adopted in order to evaluate the dynamic response behaviour of multi-storey building structure isolated with HDRB-LRB system. Moreover, the performances of multi-storey structures with the rubber-steel bearing systems are duly appraised. The excitation-response relations for ground excitation are perfectly formulated to acquire responses of isolated based building. Output results attained from the analyses in static, free vibration and frequency domain are compared. Summarised major findings and characteristics are stated as follows:

1) Dynamic frequency domain analysis is a very effective tool to cope up with the structural behaviour, avoiding extensive computational effort as well as time for mutually conventional and isolated based structure.

2) Bi-linear model and equivalent linear model are excellently capable to cope with the essential features of LRB and HDRB, respectively. Thus, the nonlinear behaviours of the entire structural system are duly incorporated.

3) Wide-ranging sensitivity studies to find the influence of rubber-steel bearing on both isolator and superstructure of isolated structure are possible by the developed model.

4) Displacement and acceleration excursions of the superstructure without isolator are much more sensitive, while both the responses reduce significantly at insertion of rubber-steel bearing.

5) Maximum horizontal displacements weighed at support level were well below the expected static design displacement of isolators.

6) The rubber-steel bearings are innovative and efficacious devices to mitigate displacement than acceleration. Superstructure takes comparatively extensive acceleration response, while only small displacement is experienced especially for stiffer superstructures.

7) The storey drifts of the building are dissimilar to the rigid body motion because of flexibility of the superstructure. The more the period is prolonged, the lesser the storey accelerations and storey drifts are experienced by the superstructure. Displacement increases with period in the base isolated building for all cases.

8) The base shears and base moments in each direction decrease in momentous manner for isolated structure compared to the fixed building. Such decrement ensures momentous structural savings and subsequently predicts economic benefits.

9) Increasing the natural period of structure in case of base isolating system can more effectively reduce responses of superstructures than fixed based case.

10) Due to low frequencies through base isolation, spectral horizontal accelerations are muscularly reduced as expected compare to corresponding accelerations of non-isolated building.

11) A consistent base isolation is obtained by proper incorporation of the rubber-steel bearings. The base excitation period limits within the order of 3. The actual isolation frequency ranges are in the usual range $0.3-0.5 \mathrm{~Hz}$, ensuring moderate floor accelerations together with acceptable rigid body displacements. 


\section{Acknowledgement}

The authors gratefully acknowledge the support given by University of Malaya (UM) for funding the study through High Impact Research Grant H-16001-00-D000036 to enhance the works coming round at success.

\section{References}

Agarwal, V. K.; Niedzwecki, J. M.; Van de Lindt, J. W. 2007. Earthquake induced pounding in friction varying base isolated buildings, Engineering Structures 29(11): 28252832. http://dx.doi.org/10.1016/j.engstruct.2007.01.026

Ariga, T.; Kanno, Y.; Takewaki, I. 2006. Resonant behaviour of base-isolated high-rise buildings under long-period ground motions, The Structural Design of Tall and Special Buildings 15(3): 325-338. http://dx.doi.org/10.1002/tal.298

Bangladesh National Building Code. 1993. BNBC. Bangladesh: Housing and Building Research Institute, Bangladesh Standard and Testing Institute.

Betti, M.; Vignoli, A. 2011. Numerical assessment of the static and seismic behaviour of the basilica of Santa Maria all'Impruneta (Italy), Construction and Building Materials 25(12): 4308-4324.

http://dx.doi.org/10.1016/j.conbuildmat.2010.12.028

Casciati, F.; Hamdaoui, K. 2008. Modelling the uncertainty in the response of a base isolator, Probabilistic Engineering Mechanics 23(4): 427-437.

http://dx.doi.org/10.1016/j.probengmech.2007.10.014

CSI Computer \& Structures Inc. SAP2000. 2004. Linear and nonlinear static and dynamic analysis of three-dimensional structures. Berkeley (CA): Computer \& Structures, Inc.

Dall'Asta, A.; Ragni, L. 2006. Experimental tests and analytical model of high damping rubber dissipating devices, Engineering Structures 28(13): 1874-1884. http://dx.doi.org/10.1016/j.engstruct.2006.03.025

Dall'Asta, A.; Ragni, L. 2008. Nonlinear behavior of dynamic systems with high damping rubber devices, Engineering Structures 30(12): 3610-3618. http://dx.doi.org/10.1016/j.engstruct.2008.06.003

Deb, S. 2004. Seismic base isolation-an overview, Current Science 87(10): 1426-1430.

Dicleli, M.; Buddaram, S. 2007. Comprehensive evaluation of equivalent linear analysis method for seismic-isolated structures represented by sdof systems, Engineering Structures 29(8): 1653-1663. http://dx.doi.org/10.1016/j.engstruct.2006.09.013

Ho, J. C.-M.; Zhou, K. J.-H. 2011. Limited deformability design of high-strength concrete beams in low to moderate seismicity regions, Journal of Civil Engineering and Management 17(3): 409-423. http://dx.doi.org/10.3846/13923730.2011.594219

Islam, A. B. M. S.; Hussain, R. R.; Jameel, M.; Jumaat, M. Z. 2012a. Non-linear time domain analysis of base isolated multi-storey building under site specific bi-directional seismic loading, Automation in Construction 22: 554-566. http://dx.doi.org/10.1016/j.autcon.2011.11.017

Islam, A. B. M. S.; Jameel, M.; Uddin, M. A.; Ahmad, S. I. 2011a. Simplified design guidelines for seismic base isolation in multi-storey buildings for Bangladesh National Building Code (BNBC), International Journal of the Physical Sciences 6(23): 5467-5486.

Islam, A. B. M. S.; Jameel, M.; Rahman, M. A.; Jumaat, M. Z. 2011b. Earthquake time history for Dhaka, Bangladesh as competent seismic record, International Journal of the Physical Sciences 6(16): 3921-3926.

Islam, A. B. M. S.; Jameel, M.; Uddin M. A.; Jumaat, M. Z. 2012b. Competent building elevation for incorporating base isolation in aseismic structure, Procedia Engineering 50: 882-892.

http://dx.doi.org/10.1016/j.proeng.2012.10.096

Islam, A. B. M. S.; Hussain, R. R.; Jumaat, M. Z.; Rahman M. A. 2013a. Nonlinear dynamically automated excursions for rubber-steel bearing isolation in multi-storey construction, Automation in Construction 30: 265-275. http://dx.doi.org/10.1016/j.autcon.2012.11.010

Islam, A. B. M. S.; Jameel, M.; Jumaat, M. Z.; Rahman M. M. 2013b. Optimization in structural altitude for seismic base isolation at medium risk earthquake disaster region, Disaster Advances 6(1): 23-34.

Islam, A. B. M. S.; Ahmad, S. I.; Jumaat, M. Z.; Hussain, R. 2013c. Efficient design in building construction with rubber bearing in medium risk seismicity: case study \& assessment, Journal of Civil Engineering and Management http://dx.doi.org/10.3846/13923730.2013.801910.

Ismail, M.; Rodellar, J.; Ikhouane, F. 2010. An innovative isolation device for aseismic design, Engineering Structures 32(4): 1168-1183. http://dx.doi.org/10.1016/j.engstruct.2009.12.043

Jameel, M.; Islam, A. B. M. S.; Hussain, R. R.; Khaleel, M. 2012. Optimum structural modelling for tall buildings, The Structural Design of Tall and Special Building. 22(15): 1173-1185.

Jangid, R. S. 2007. Optimum lead-rubber isolation bearings for nearfault motions, Engineering Structures 29(10): 2503-2513. http://dx.doi.org/10.1016/j.engstruct.2006.12.010

Kelly, T. E. 2001. Base isolation of structures: design guidelines. Wellington: Holmes Consulting Group Ltd. p. 229.

Kelly, T. E.; Robinson, W. H.; Skinner, R. I. 2006. Seismic isolation for designers and structural engineers. Robinson seismic Ltd. Available from Internet: http://www.robinsonseismic.com/book-seismic-isolation.html

Kilar, V.; Koren, D. 2009. Seismic behaviour of asymmetric base isolated structures with various distributions of isolators, Engineering Structures 31(4): 910-921. http://dx.doi.org/10.1016/j.engstruct.2008.12.006

Komodromos, P. 2008. Simulation of the earthquake-induced pounding of seismically isolated buildings, Computers \& Structures 86(7-8): 618-626. http://dx.doi.org/10.1016/j.compstruc.2007.08.001

Lu, L.-Y.; Lin, G.-L. 2008. Predictive control of smart isolation system for precision equipment subjected to near-fault earthquakes, Engineering Structures 30(11): 3045-3064. http://dx.doi.org/10.1016/j.engstruct.2008.04.016

Matsagar, V. A.; Jangid, R. S. 2004. Influence of isolator characteristics on the response of base-isolated structures, Engineering Structures 26(12): 1735-1749. http://dx.doi.org/10.1016/j.engstruct.2004.06.011

Micheli, I.; Cardini, S.; Colaiuda, A.; Turroni, P. 2004. Investigation upon the dynamic structural response of a nuclear plant on aseismic isolating devices, Nuclear Engineering and Design 228(1-3): 319-343.

http://dx.doi.org/10.1016/j.nucengdes.2003.06.028

Olsen, A.; Aagaard, B.; Heaton, T. 2008. Long-period building response to earthquakes in the San Francisco Bay area, Bulletin of the Seismological Society of America 98(2): 1047. http://dx.doi.org/10.1785/0120060408

Patil, V. B.; Jangid, R. S. 2011. Optimum multiple tuned mass dampers for the wind excited benchmark building, Journal 
of Civil Engineering and Management 17(4): 540-557. http://dx.doi.org/10.3846/13923730.2011.619325

Pocanschi, A.; Phocas, M. C. 2007. Earthquake isolator with progressive nonlinear deformability, Engineering Structures 29(10): 2586-2592. http://dx.doi.org/10.1016/j.engstruct.2006.12.016

Providakis, C. P. 2008. Effect of LRB isolators and supplemental viscous dampers on seismic isolated buildings under near-fault excitations, Engineering Structures 30(5): 11871198. http://dx.doi.org/10.1016/j.engstruct.2007.07.020

Seçer, M.; Bozdağ, Ö. 2011. Effect of x-bracing configuration on earthquake damage cost of steel building, Journal of Civil
Engineering and Management 17(3): 348-356. http://dx.doi.org/10.3846/13923730.2011.594223

Spyrakos, C. C.; Koutromanos, I. A.; Maniatakis, C. A. 2009. Seismic response of base-isolated buildings including soilstructure interaction, Soil Dynamics and Earthquake Engineering 29(4): 658-668. http://dx.doi.org/10.1016/j.soildyn.2008.07.002

Win, A. 2008. Analysis and design of base isolation for multistoreyed building, in The Third GMSARN International Conference on "Sustainable Development: Issues and Prospects for the Greater Mekong Subregion", 12-14 November, 2008, Kunming, China.

A. B. M. Saiful ISLAM. A Research Fellow after receiving his $\mathrm{PhD}$ at the Department of Civil Engineering, University of Malaya, Malaysia. He completed his BSc in Civil Engineering and MSc in Structural Engineering from Bangladesh university of Engineering and Technology (BUET), Bangladesh. He is a member of Institution of Engineers, Bangladesh and American Society of Civil Engineers (ASCE). His research interests include offshore structures, nonlinear dynamics, finite element modelling, seismic protection, base isolation, pounding and special tall buildings.

Mohd Zamin JUMAAT. A Professor and a Head of the Department of Civil Engineering, University of Malaya, Malaysia. $\mathrm{He}$ is a member of Institution of Engineers, Malaysia, and a member of the Drafting Code Committee for reinforced concrete structures. His research interests include behaviour of offshore structures, reinforced concrete structural elements, concrete materials, self-consolidating concrete, lightweight concrete and green concrete.

Raja HUSSAIN. An Assistant Professor in CoE-CRT, Department of Civil Engineering, College of Engineering, King Saud University, Riyadh, Saudi Arabia. He received his PhD and MSc in Civil Engineering from the University of Tokyo, Japan, for which he was ranked outstanding and was awarded best research thesis award from the University of Tokyo. He received his $\mathrm{PhD}$ in record short period of just two years. He has authored more than 75 publications in less than 5 years of his post-PhD tenure and has received several awards, prizes and distinctions throughout his research and academic career.

Md Ashraful ALAM. A Senior Lecturer in the Department of Civil Engineering, University Tenaga Nasional, Kuala Lumpur, Malaysia. He completed his PhD from the University of Malaya, Malaysia. His research interests include the analysis and design of structures, reinforced concrete structural elements, concrete materials and structural strengthening. 